\title{
Review Article \\ Implications of Renal Denervation Therapy in Patients with Sleep Apnea
}

\author{
Fernando Jaén-Águila, José Antonio Vargas-Hitos, and Juan Diego Mediavilla-García
}

Cardiovascular Risk Unit, Department of Internal Medicine, University Hospital Complex City of Granada, Avenida Fuerzas Armadas 2, 18014 Granada, Spain

Correspondence should be addressed to Fernando Jaén-Águila; fer0602@gmail.com

Received 15 November 2014; Accepted 8 February 2015

Academic Editor: Samy I. McFarlane

Copyright (C) 2015 Fernando Jaén-Águila et al. This is an open access article distributed under the Creative Commons Attribution License, which permits unrestricted use, distribution, and reproduction in any medium, provided the original work is properly cited.

\begin{abstract}
Obstructive sleep apnea (OSA) syndrome is a prevalent condition characterized by repeated episodes of obstruction of the upper airway, leading to intermittent hypoxemia and important endothelial and anatomical dysfunctions that cause cardiovascular and cerebrovascular disease. The finding of the relationship between OSA and hypertension, especially resistant hypertension (RHT), has increased the interest in therapeutic strategies that affect renal sympathetic activity in these patients. The observational studies published until now demonstrated that renal denervation therapy can reduce the severity of OSA syndrome. Renal sympathetic denervation $(\mathrm{RDN})$ could be a future therapeutic possibility for conditions other than RHT, such as atrial fibrillation, heart failure, obesity, and OSA syndrome, where renal sympathetic system plays an important physiological role. The aim of this review was to elucidate the implications of renal sympathetic activity in OSA syndrome.
\end{abstract}

\section{Introduction}

The apnea-hypopnea sleep (AHS) syndrome was firstly described in 1976 by Guilleminault et al. [1]. It affects 3-7\% of the general population and is characterized by repeated episodes of obstruction of the upper airway during sleep.

The apnea-hypopnea index (AHI) is used to measure the severity of obstructive apnea. Diagnosis is defined as an AHI $>5$ accompanied by disease-related symptoms [2].

OSA syndrome and its relationship with HT have been well established [3]. An increase in the AHI implies an increased risk of developing HT [4]. The factors involved in this cardiovascular issue are endothelial dysfunction and systemic inflammation, which lead to activation of the sympathetic tone. Excess sympathetic tone plays a decisive role in the development of RHT [5]. It is an independent risk factor for cardiovascular risk, which is responsible for ischemic heart disease, atrial fibrillation, heart failure, stroke, and sudden death [6]. Two-thirds of the patients with acute ischemic stroke develop OSA syndrome. The presence of
OSA syndrome in patients who suffered from cerebrovascular events determines impairment of cognitive function during the acute and subacute phases of stroke [7].

HT is a major public health issue worldwide, not only because of its high prevalence (30-45\% of the general population, reaching $60 \%$ in the elderly), but also because of the impact on cardiovascular morbidity and mortality. Population studies have reported that one-third of the hypertensive patients develop apnea-hypopnea sleep (AHS) syndrome and that $40 \%$ of patients with AHS syndrome are hypertensive $[4,8]$.

It has been observed that OSA syndrome is present in $75 \%$ of patients diagnosed with RHT; nevertheless, its prevalence is much lower (38\%) in hypertensive patients with controlled blood pressure (BP) [9]. Cardiovascular risk was found to be significantly higher in patients with RHT than in those without RHT [10]; this association opens the possibility that OSA syndrome and HT share similar physiopathological mechanisms contributing to both pathological processes. Recent expert information recommends the treatment of 
OSA syndrome as part of the management of patients with RHT [11-13].

The increase of sympathetic activity is involved in the development, management, and the evolution of the hypertensive state of patients with OSA syndrome. It implies that sympathetic deactivation can be seen as a goal of treatment. Small observational studies published so far reported that RDN can decrease the severity of OSA syndrome. RDN therapy is having an important role in the treatment of other diseases apart from HT; in fact, beneficial effects of RDN therapy in diseases other than HT where the renal sympathetic system plays an important role have been reported, such as atrial fibrillation, heart failure, obesity, or diabetes. The aim of this review was to elucidate the implication of renal sympathetic activity on the OSA syndrome.

\section{Physiopathological Factors of OSA Syndrome}

Many physiopathological factors have been described involved in the development of AHS syndrome. Some of the factors that promote the collapse of the upper airway are the narrowing of this airway, excessive loss of muscle tone, and defective upper airway protective reflexes mediated by overstimulation of sympathetic nervous system [14-16].

The neurophysiological factors involved in the development of HT in patients with AHS syndrome are interacting with each other [17]. Increased sympathetic tone implies the following physiological changes (Figure 1):

(1) Intermittent hypoxia due to apnea and hypopnea triggers an excess of sympathetic activity by the activation of the carotid chemoreceptors; it leads to direct vasoconstriction and the subsequent stimulation of the renin-angiotensin-aldosterone system (RAAS) as well as increased levels of endothelin and angiotensin II. Activation of the renin-angiotensin axis produces fluid retention due to sodium reabsorption; it seems to lead to edema in the peripharyngeal walls, which predisposes to upper airway obstruction $[18,19]$.

(2) The increase in the sympathetic tone in patients with OSA syndrome produces renal activation of the autonomic nervous system. The kidneys are connected to the brain by afferent and efferent pathways. Hyperactivity of the autonomic nervous system stimulates renin release from the juxtaglomerular apparatus, then activating $\beta 1$ adrenoreceptors; this increases the circulating volume when sodium retention increases, and renal blood flow decreases through the $\alpha 1$ adrenoreceptors.

Renal afferent activation determines an increase of the sympathetic activity in the central nervous system (CNS), involving the vascular system, heart, and the other peripheral organs, leading to HT and its degree of severity [20].

(3) Sympathetic hyperactivity reduces the dilating effect of the upper airway muscles mediated by the genioglossal nerve and predisposes to pharyngeal obstruction [21]. Excess of sympathetic tone increases pharyngeal wall thickness and favors peripharyngeal fluid accumulation promoting the development of OSA syndrome, with recurrent episodes of hypoxia, sleep fragmentation, and the subsequent increase of the sympathetic tone [22].

(4) The physiological stimuli associated with apnea produce the formation of endogenous vasoactive substances and decrease the levels of nitric oxide, a potent vasodilator. It has been demonstrated that the use of CPAP during the night increases the circulatory levels of nitric oxide. Ischemic and reperfusion events associated with apnea lead to endothelial injury [23].

\section{Results of the Major Clinical Studies in Patients with OSA Syndrome Undergoing Renal Sympathetic Denervation}

Symplicity HTN-1, HTN-2, and HTN-3 trials are the most relevant studies concerning the clinical use of RDN therapy [30-32]. The initial studies demonstrated a significant decrease of BP levels at 3 years in patients with RHT.

Nevertheless, the Symplicity HTN-3 study which enrolled 535 randomized patients with a 6-month follow-up was not able to confirm the results previously obtained. There was no significant between-group difference in the change in office blood pressure at 6 months. This finding has questioned its efficacy. However, the responses with regard to systolic and diastolic blood pressure were significantly greater in the denervation group than in the sham-procedure group. It seems to be demonstrated that RDN therapy reduces renal sympathetic secretion and leads to a systemic decrease in sympathetic tone.

Some small studies have demonstrated a significant decrease of AHI in patients with OSA syndrome after undergoing RDN; this can explain the relationship between HT, OSA syndrome, and excess sympathetic tone. RDN has the potential effect of decreasing sympathetic overactivity in patients with OSA syndrome [33].

The first studies demonstrating this relationship were carried out in animal models. RDN decreased BP rises and the incidence of secondary arrhythmias, during postapneic periods in OSA syndrome models. This decreased the susceptibility of these animal models to develop atrial fibrillation [34]. Furthermore, these effects seemed to be independent of the decreases found in BP levels, which gave more relevance to the role of the central sympathetic secretion.

A recent meta-analysis published by Shantha and Pancholy [24] included 5 relevant clinical studies [25-29] in humans (Table 1) with a total of 49 patients studied.

Three of these studies were carried out in Europe, where the RDN technique is more accepted. Of the five studies, that of Witkowski et al. evaluated specifically the role of RDN in the AHI, BP, and glycemic control. Although the number of patients involved in the study was small $(n=10)$, it showed relevant results. AHI was measured in the 10 patients by polysomnography, before and 6 months after undergoing $\mathrm{RDN}$. The authors reported a decrease in the severity of 


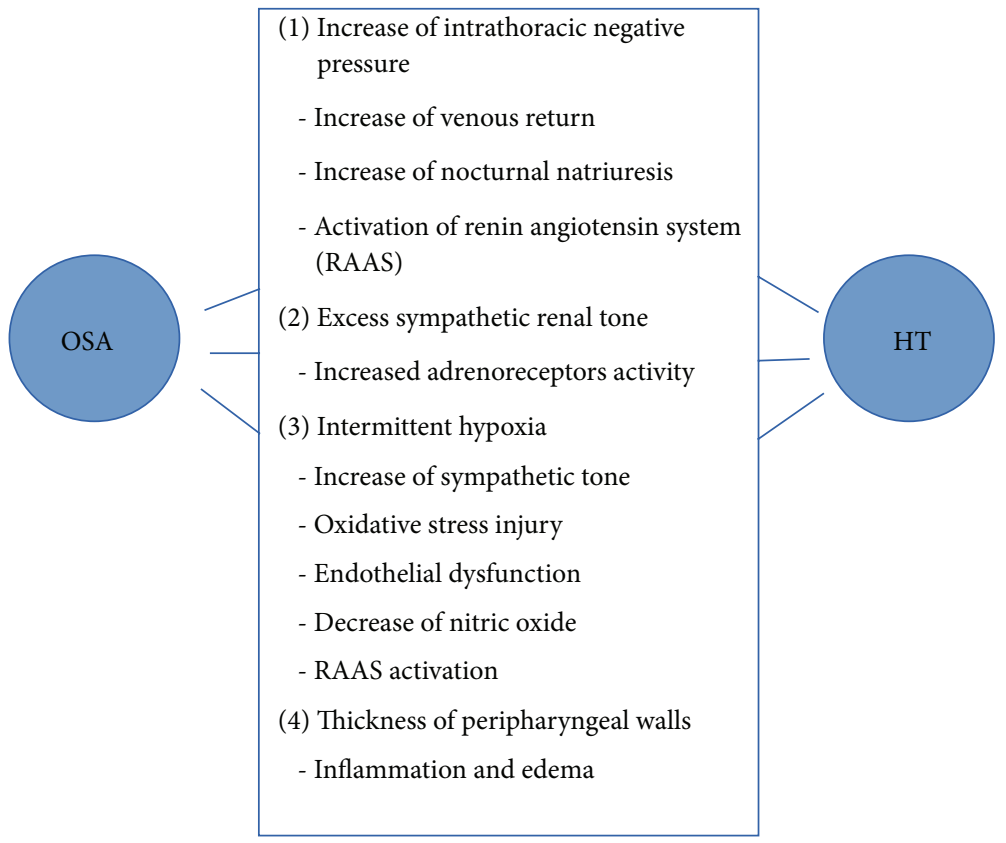

FIGURE 1: Relationship between OSA syndrome and arterial hypertension (HT).

TABLE 1: Major clinical studies carried out in patients with AHS syndrome undergoing RND therapy. Modified by Shantha and Pancholy [24].

\begin{tabular}{|c|c|c|c|c|c|}
\hline Author & Year & Patients $(n)$ & OSA patients & AHI pre-RDN & AHI post-RDN (6 months) \\
\hline Damascelli et al. [25] & 2013 & 24 RHT patients & 2 & 63.3 & 26.5 \\
\hline Schmiedel et al. [26] & 2013 & 40 RHT patients & 16 & 25 & 17 \\
\hline Thakur et al. [27] & 2013 & 21 RHT patients & 6 & 21.1 & 10.5 \\
\hline Witkowski et al. [28] & 2011 & $\begin{array}{l}10 \text { RHT patients, } \\
\text { all with OSA }\end{array}$ & $\begin{array}{l}10 \\
10\end{array}$ & 30.7 & 16.1 \\
\hline Zhao et al. [29] & 2013 & 31 RHT patients & 15 & 32 & 27 \\
\hline
\end{tabular}

Resistant hypertension $=$ RHT; obstructive sleep apnea = OSA; apnea-hypopnea index = AHI; renal sympathetic denervation = RDN; apnea-hypopnea sleep syndrome $=$ AHS .

OSA syndrome in the patients after RDN, although without statistical significance due to the small size of the sample. The authors also reported that RDN therapy significantly decreased BP levels and improved the glycemic control of patients [28].

Zhao et al. [29] compared the response a total of 31 patients with OSA syndrome, 16 of them undergoing CPAP treatment and the other 15 treated with RDN.

The authors concluded that both CPAP and RDN treatments decreased OSA severity in the patients. They reported that the efficacy of CPAP treatment was higher in patients undergoing this therapy, since 6 months after treatments the AHI was lower in the patients treated with CPAP than in those who underwent RDN.

All 5 studies of the meta-analysis showed significant changes in BP after RDN, with a 6-month follow-up. The decrease in SBP was greater than in DBP. Furthermore, there were some evidences that the decrease was independent of the improvement in the severity of OSA found in the patients. The meta-analysis included 49 patients followed up during 6 months. The AHI was measured in all of them before and after RDN. The results demonstrated a reduction in AHI 6 months after RDN, as well as less nocturnal awakenings and improvement of nocturnal oxygen saturation.

\section{Treatment of Sleep Apnea in Patients with Hypertension}

Continuous positive airway pressure (CPAP), described by Sullivan et al. in 1981, is the treatment of choice for sleep apnea in hypertensive patients [35]. It improves the apnea episodes and prevents oxygen desaturation and the arousals (electroencephalographic awakenings), which results in a reduction in the morbidity and mortality of these patients [36].

Montesi et al. [37] carried out a systematic review and meta-analysis in 2012, which included 32 studies and a total of 2303 patients. The use of CPAP therapy was associated with a significant decrease in SBP, DBP, and mean BP values. BP decreases were mainly found in patients with higher daytime sleepiness, more severe OSA, and more compliance to CPAP therapy. 
The mechanisms of the association between $\mathrm{BP}$ and daytime sleepiness could be related to the arousals, which occur at the end of the respiratory events, coinciding with repeated BP surges. Intermittent ischemic episodes increase $\mathrm{BP}$ by the activation of type I angiotensin II receptor. It seems that overactivation of the renin-angiotensin axis occurs independently of other factors [38]. RDN could have an important role in patients with higher sympathetic stimulation.

Although the hypotensive effect of CPAP seems to be moderate, decreases of $5 \mathrm{~mm} \mathrm{Hg}$ in DBP reduce the risk of cerebrovascular accidents by $42 \%$ and all cardiovascular events by $31 \%$ [39].

Significant decrease of BP only 3 weeks after onset of CPAP treatment reinforces the importance of studying and treating OSA syndrome in patients with RHT.

\section{Conclusions}

CPAP is the treatment of choice in the management of patients with OSA; its use in the treatment of RHT is becoming increasingly more widespread. The important implications of morbidity in OSA syndrome make it necessary to seek new therapies that intervene in the physiological mechanisms related to cardiovascular events in these patients. Nowadays, it has been demonstrated that RDN improves the severity of OSA syndrome in patients with RHT. In this respect, $\mathrm{RDN}$ treatment could be considered in patients with excess sympathetic tone. Nevertheless, further clinical trial should be required before renal denervation can be applied to the study of OSA and other conditions such as obesity hypertension.

\section{Disclosure}

The authors agree with all criteria of publication of this journal.

\section{Conflict of Interests}

The authors declare no conflict of interests.

\section{References}

[1] C. Guilleminault, A. Tilkian, and W. C. Dement, "Sleep apnea syndromes," Annual Review of Medicine, vol. 27, pp. 465-485, 1976.

[2] J. Durán-Cantolla, F. J. Puertas-Cuesta, G. Pin-Arboledas, and J. S. María-Cano, "National consensus document about sleep apnea-Hypopnea syndrome," Archivos de Bronconeumología, vol. 41, pp. 1-110, 2005.

[3] J.-P. Baguet, G. Barone-Rochette, and J.-L. Pépin, "Hypertension and obstructive sleep apnoea syndrome: current perspectives," Journal of Human Hypertension, vol. 23, no. 7, pp. 431443, 2009.

[4] P. E. Peppard, T. Young, M. Palta, and J. Skatrud, "Prospective study of the association between sleep-disordered breathing and hypertension," The New England Journal of Medicine, vol. 342, no. 19, pp. 1378-1384, 2000.
[5] A. G. Logan, S. M. Perlikowski, A. Mente et al., "High prevalence of unrecognized sleep apnoea in drug-resistant hypertension," Journal of Hypertension, vol. 19, no. 12, pp. 2271-2277, 2001.

[6] V. K. Somers, D. P. White, R. Amin et al., "Sleep apnea and cardiovascular disease: an American Heart Association/american College Of Cardiology Foundation Scientific Statement from the American Heart Association Council for High Blood Pressure Research Professional Education Committee, Council on Clinical Cardiology, Stroke Council, and Council On Cardiovascular Nursing. In collaboration with the National Heart, Lung, and Blood Institute National Center on Sleep Disorders Research (National Institutes of Health)," Circulation, vol. 118, no. 10, pp. 1080-1111, 2008.

[7] H. K. Yaggi, J. Concato, W. N. Kernan, J. H. Lichtman, L. M. Brass, and V. Mohsenin, "Obstructive sleep apnea as a risk factor for stroke and death," The New England Journal of Medicine, vol. 353, no. 19, pp. 2034-2041, 2005.

[8] J. C. T. Pepperell, S. Ramdassingh-Dow, N. Crosthwaite et al., "Ambulatory blood pressure after therapeutic and subtherapeutic nasal continuous positive airway pressure for obstructive sleep apnoea: a randomised parallel trial," The Lancet, vol. 359, no. 9302, pp. 204-210, 2002.

[9] S. C. Gonsalves, D. Martínez, and M. Gus, "Obstructive sleep apnea and resistant hypertension: a case control study," Chest, vol. 131, no. 2, pp. 453-459, 2007.

[10] S. L. Daugherty, J. D. Powers, D. J. Magid et al., "Incidence and prognosis of resistant hypertension in hypertensive patients," Circulation, vol. 125, no. 13, pp. 1635-1642, 2012.

[11] N. Kartali, E. Daskalopoulou, P. Geleris et al., "The effect of continuous positive airway pressure therapy on blood pressure and arterial stiffness in hypertensive patients with obstructive sleep apnea," Sleep and Breathing, vol. 18, no. 3, pp. 635-640, 2014.

[12] C. Tsioufis, A. Kasiakogias, C. Thomopoulos, A. Manolis, and C. Stefanadis, "Managing hypertension in obstructive sleep apnea: the interplay of continuous positive airway pressure, medication and chronotherapy," Journal of Hypertension, vol. 28, no. 5, pp. 875-882, 2010

[13] G. Mancia, R. Fagard, K. Narkiewicz et al., "2013 ESH/ESC Guidelines for the management of arterial hypertension: The Task Force for the management of arterial hypertension of the European Society of Hypertension (ESH) and of the European Society of Cardiology (ESC)," European Heart Journal, vol. 34, pp. 2159-2219, 2013.

[14] S. Isono, J. E. Remmers, A. Tanaka, Y. Sho, J. Sato, and T. Nishino, "Anatomy of pharynx in patients with obstructive sleep apnea and in normal subjects," Journal of Applied Physiology, vol. 82, no. 4, pp. 1319-1326, 1997.

[15] W. S. Mezzanotte, D. J. Tangel, and D. P. White, "Waking genioglossal electromyogram in sleep apnea patients versus normal controls (a neuromuscular compensatory mechanism)," The Journal of Clinical Investigation, vol. 89, no. 5, pp. 1571-1579, 1992.

[16] V. K. Somers, M. E. Dyken, M. P. Clary, and F. M. Abboud, "Sympathetic neural mechanisms in obstructive sleep apnea," The Journal of Clinical Investigation, vol. 96, no. 4, pp. 1897-1904, 1995.

[17] K. Narkiewicz, P. J. H. van de Borne, N. Montano, M. E. Dyken, B. G. Phillips, and V. K. Somers, "Contribution of tonic chemoreflex activation to sympathetic activity and blood pressure in patients with obstructive sleep apnea," Circulation, vol. 97, no. 10, pp. 943-945, 1998. 
[18] K. K. Gaddam, M. K. Nishizaka, M. N. Pratt-Ubunama et al., "Characterization of resistant hypertension: association between resistant hypertension, aldosterone, and persistent intravascular volume expansion," Archives of Internal Medicine, vol. 168, no. 11, pp. 1159-1164, 2008.

[19] R. J. Schwab, K. B. Gupta, W. B. Gefter, L. J. Metzger, E. A. Hoffman, and A. I. Pack, "Upper airway and soft tissue anatomy in normal subjects and patients with sleep-disordered breathing: significance of the lateral pharyngeal walls," American Journal of Respiratory and Critical Care Medicine, vol. 152, no. 5, pp. 16731689, 1995.

[20] W. D. Hall, "Risk reduction associated with lowering systolic blood pressure: review of clinical trial data," The American Heart Journal, vol. 138, no. 3, pp. S225-S230, 1999.

[21] G. Grassi, B. M. Cattaneo, G. Seravalle, A. Lanfranchi, and G. Mancia, "Baroreflex control of sympathetic nerve activity in essential and secondary hypertension," Hypertension, vol. 31, no. 1, pp. 68-72, 1998.

[22] J. A. Hedner, I. Wilcox, L. Laks, R. R. Grunstein, and C. E. Sullivan, "A specific and potent pressor effect of hypoxia in patients with sleep apnea," The American Review of Respiratory Disease, vol. 146, no. 5, pp. 1240-1245, 1992.

[23] R. Schulz, D. Schmidt, A. Blum et al., "Decreased plasma levels of nitric oxide derivatives in obstructive sleep apnoea: response to CPAP therapy," Thorax, vol. 55, no. 12, pp. 1046-1051, 2000.

[24] G. P. S. Shantha and S. B. Pancholy, "Effect of renal sympathetic denervation on apnea-hypopnea index in patients with obstructive sleep apnea: a systematic review and meta-analysis," Sleep and Breathing, 2014.

[25] B. Damascelli, G. Patelli, V. Tichá et al., "Catheter-based radiofrequency renal sympathetic denervation for resistant hypertension," Journal of Vascular and Interventional Radiology, vol. 24, no. 5, pp. 632-639, 2013.

[26] L. Schmiedel, A. Traenkner, N. Schmiedehausen, R. H. Strasser, and H. Schroetter, "The failing effects of renal sympathetic denervation in patients with drug resistant hypertension and untreated obstructive sleep apnea," European Heart Journal, vol. 34, pp. 823-824, 2013.

[27] D. Thakur, N. Zimmerman, H. Rajebi, and M. R. Rajebi, "Renal sympathetic denervation and resistant hypertension," Journal of Vascular and Interventional Radiology, vol. 24, pp. 145.e6-145.e7, 2013.

[28] A. Witkowski, A. Prejbisz, E. Florczak et al., "Effects of renal sympathetic denervation on blood pressure, sleep apnea course, and glycemic control in patients with resistant hypertension and sleep apnea," Hypertension, vol. 58, no. 4, pp. 559-565, 2011.

[29] M.-M. Zhao, X.-X. Tan, N. Ding, and X.-L. Zhang, "Comparison of efficacy between continuous positive airway pressure and renal artery sympathetic denervation by radiofrequency ablation in obstructive sleep apnea syndrome patients with hypertension," Zhonghua Yi Xue Za Zhi, vol. 93, no. 16, pp. 12341237, 2013.

[30] F. Mahfoud, T. F. Lüscher, B. Andersson et al., "Expert consensus document from the European Society of Cardiology on catheter-based renal denervation," European Herat Journal, vol. 34, no. 28, pp. 2149-2157, 2013.

[31] H. Krum, M. Schlaich, R. Whitbourn et al., "Catheter-based renal sympathetic denervation for resistant hypertension: a multicentre safety and proof-of-principle cohort study," The Lancet, vol. 373, no. 9671, pp. 1275-1281, 2009.

[32] M. D. Esler, H. Krum, P. A. Sobotka, M. P. Schlaich, R. E. Schmieder, and M. Böhm, "Renal sympathetic denervation in patients with treatment-resistant hypertension (the SYMPLICITY HTN-2 Trial): a randomised controlled trial," The Lancet, vol. 376, pp. 1903-1909, 2010.

[33] D. L. Bhatt, D. E. Kandzari, W. W. O’Neill et al., "A controlled trial of renal denervation for resistant hypertension," The New England Journal of Medicine, vol. 370, no. 15, pp. 1393-1401, 2014.

[34] D. Linz, F. Mahfoud, U. Schotten et al., "Renal sympathetic denervation suppresses postapneic blood pressure rises and atrial fibrillation in a model for sleep-apnea," Hypertension, vol. 60, no. 1, pp. 172-178, 2012.

[35] C. E. Sullivan, F. G. Issa, M. Berthon-Jones, and L. Eves, "Reversal of obstructive sleep apnoea by continuous positive airway pressure applied through the nares," The Lancet, vol. 1, no. 8225 , pp. 862-865, 1981.

[36] E. Ballester, J. R. Badia, L. Hernández et al., "Evidence of the effectiveness of continuous positive airway pressure in the treatment of sleep apnea/hypopnea syndrome," The American Journal of Respiratory and Critical Care Medicine, vol. 159, no. 2, pp. 495-501, 1999.

[37] S. B. Montesi, B. A. Edwards, A. Malhotra, and J. P. Bakker, "Effect of continuous positive airway pressure treatment on blood pressure: a systematic review and meta-analysis of randomized controlled trials," Journal of Clinical Sleep Medicine, vol. 8, no. 5, pp. 587-596, 2012.

[38] G. E. Foster, P. J. Hanly, S. B. Ahmed, A. E. Beaudin, V. Pialoux, and M. J. Poulin, "Intermittent hypoxia increases arterial blood pressure in humans through a renin-angiotensin system-dependent mechanism," Hypertension, vol. 56, no. 3, pp. 369-377, 2010

[39] W. D. Hall, "Risk reduction associated with lowering systolic blood pressure: review of clinical trial data," American Heart Journal, vol. 138, no. 3, pp. S225-S230, 1999. 


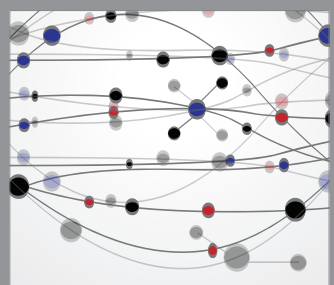

The Scientific World Journal
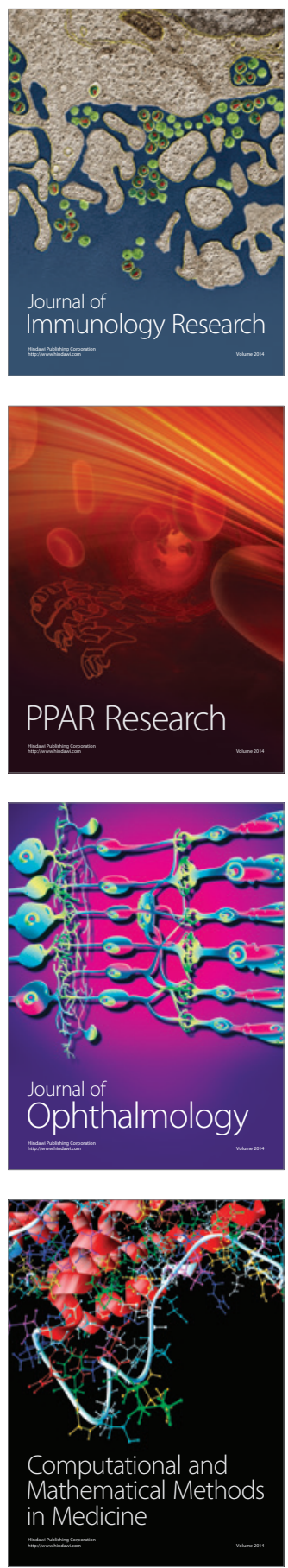

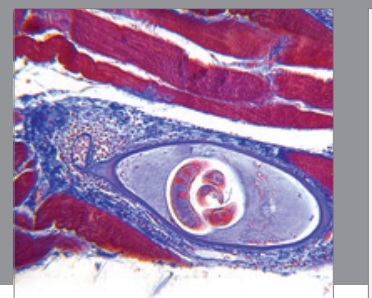

Gastroenterology

Research and Practice
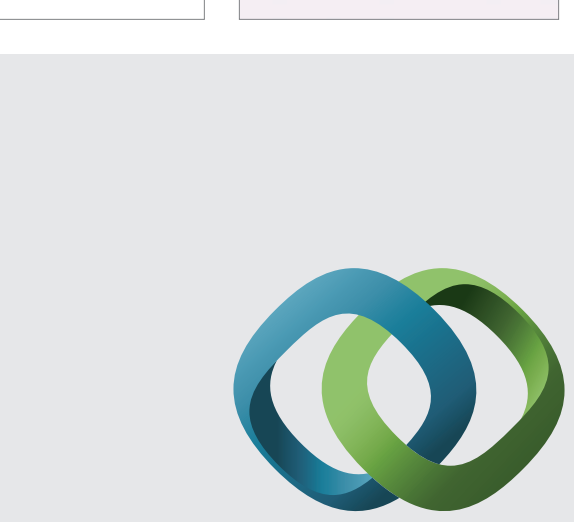

\section{Hindawi}

Submit your manuscripts at

http://www.hindawi.com
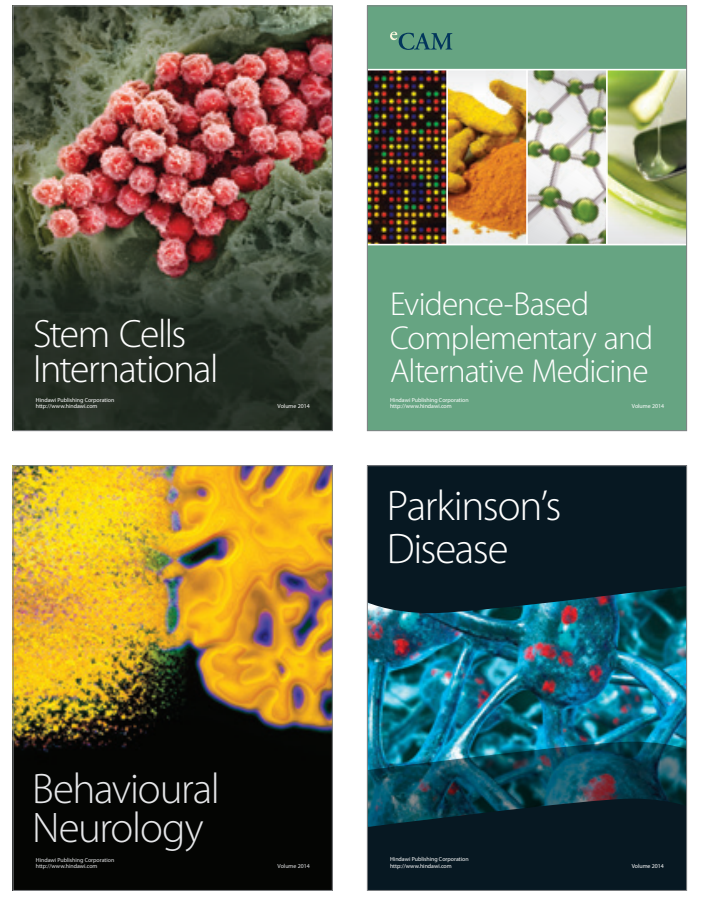
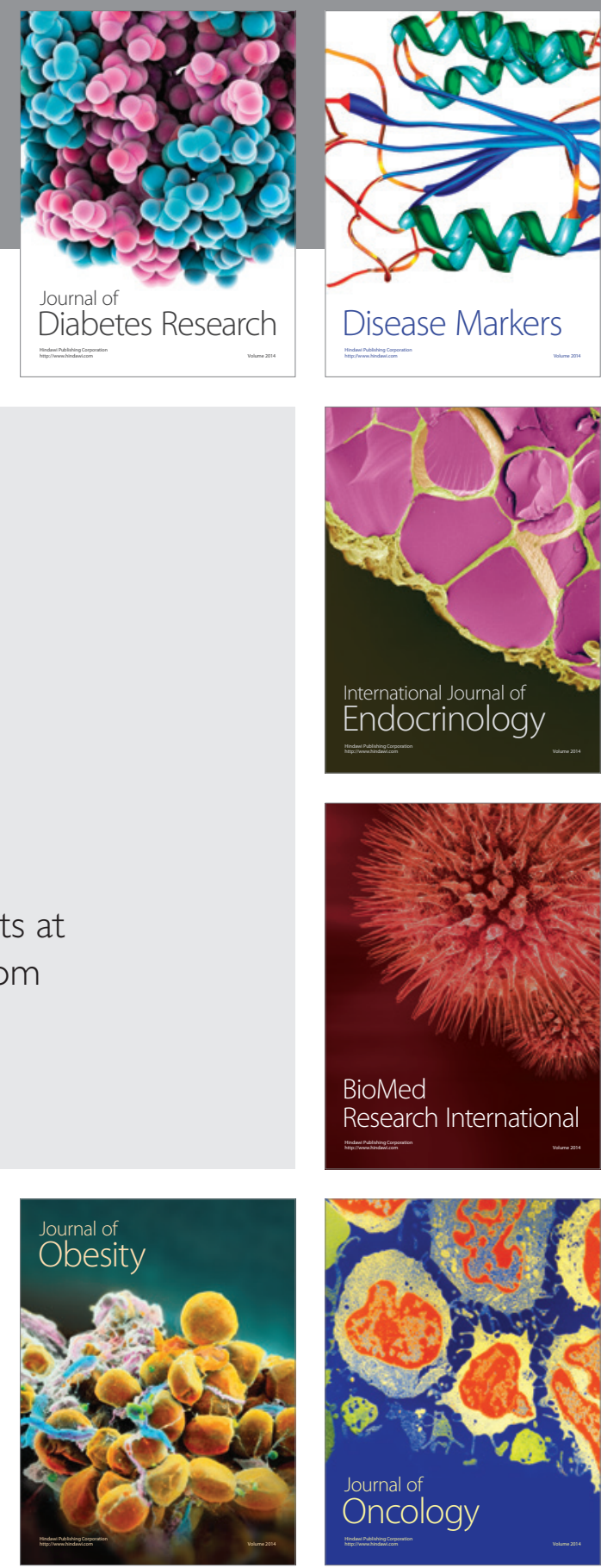

Disease Markers
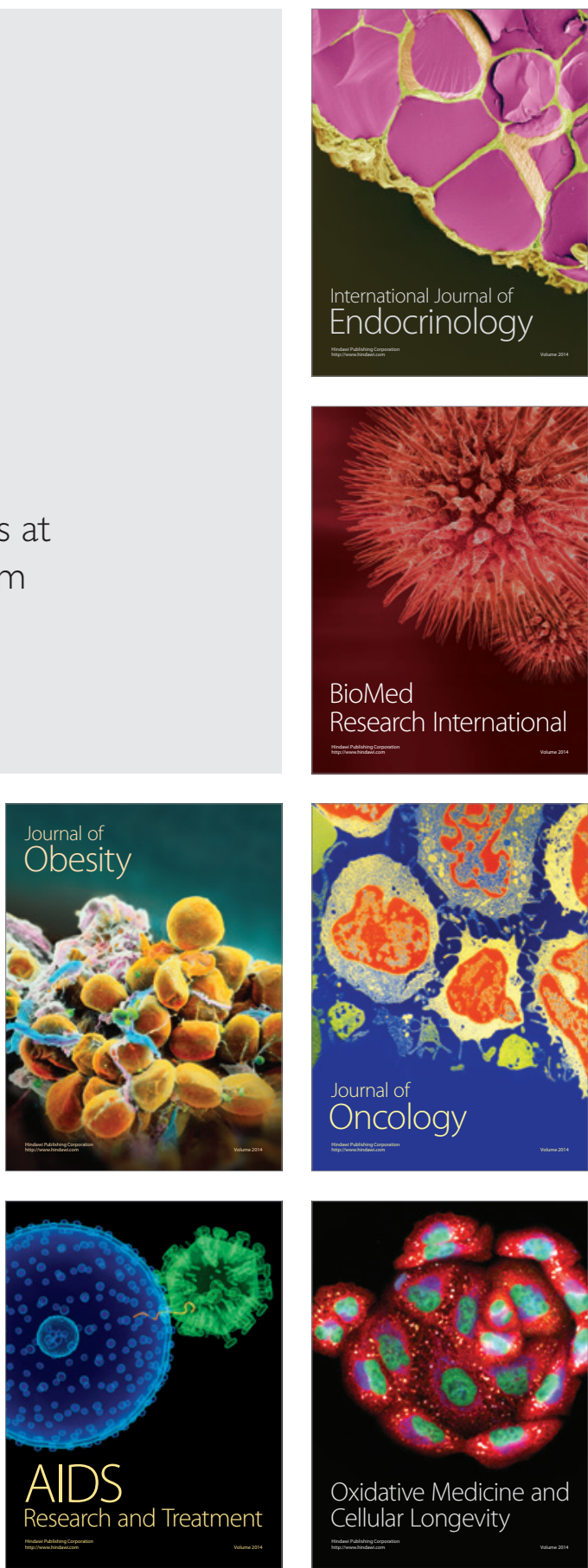